\title{
On the Development of a Modified Triangular Patch Antenna Array for 4.9 GHz Public Safety WLAN
}

\author{
Gurmeet Singh $^{1}$, A.P. Singh ${ }^{2}$ \\ ${ }^{12}$ Department of Electronics and Communication Engineering, Sant Longowal Institute of engineering and Technology, \\ Longowal, Punjab, India \\ *corresponding author, E-mail: sguru221@gmail. com
}

\begin{abstract}
The present paper reports on the development of a Novel Patch Antenna Array for 4.9 GHz Public Safety WLAN applications. In today's era of advanced technology, high speed video surveillance is very crucial from security point of view. Public safety surveillance services below $1 \mathrm{GHz}$ are mainly used in voice surveillance services, whereas 4.9 $\mathrm{GHz}$ Public Safety WLAN is used for video surveillance services. Accordingly, in this work, $2 \times 2$ element antenna array is designed on FR4 substrate using modified triangular patch antenna element with improved gain to the tune of $6.69 \mathrm{dBi}$. In this research work, biologically inspired Whale Optimization method is used in combination with polynomial curve-fitting technique for the optimization of three different geometrical dimensions of the patch antenna element. The optimized element is further modified geometrically by corner rounding and cut in feed to improve its performance including gain. The proposed antenna array resonates at $4.9 \mathrm{GHz}$ covering $120 \mathrm{MHz}$ bandwidth with an achievement of $-15.87 \mathrm{~dB}$ reflection coefficient and high gain. Results of simulation study are validated with measured results. The uniqueness of the proposed design lies in the achievement of a large gain using simple patch antenna array designed on readily available low cost FR4 substrate making very easy fabrication. Such an attempt has been rarely reported in the literature. However, the results of present investigations are quite convincing.
\end{abstract}

Keywords: Antenna Array, WOA, Gain, Public Safety WLAN.

\section{Introduction}

Emergency management is a public authority field usually managed by professionals. It is an interdisciplinary research field comprising of processes used to save organizations or populations from the aftermaths of wars, disasters and terrorism. There are several kinds of basic and advanced levels of search and rescue activity in emergency management. Applications of Emergency management include Public Safety, Emergency Response, Fleet Management, GPS Asset Tracking, MIMIO and Mesh Networks, in building coverage, Base Station Repeaters,
Digital and Analog Networks, Mobile Data, Video Streaming, Mobile Data Backhaul and Wireless Security Systems. Emergency management is independent but closely interconnected with the fields of law enforcement and military. Some of the large scale and cost intense single instances of emergency management in history include (a) June 2013 devastating floods and landslides at Kedarnath Temple, Uttrakhand in India, (b) 2011 earthquake and tsunami in Japan and (c) 1986 Chernobyl disaster in Ukraine. Commercial antennas for Emergency Management are categorized into three categories. The first category includes In-Building Antennas usually operating in 700 $\mathrm{MHz} \mathrm{LTE}$ to $6 \mathrm{GHz}$ spectrum. Further depending upon the type of mounts, these may be categorized as Ceiling and Wall Mount Antennas. Second category is known as Base Station Antennas operating usually in $132 \mathrm{MHz}$ to $6 \mathrm{GHz}$ spectrum with directional and omni directional radiation pattern The third type of antennas are Vehicular Antennas usually antennas operating in $27 \mathrm{MHz}$ to $6 \mathrm{GHz}$ mobile broadband with no Ground Plane Options. Such wideband and multiband antennas are featured with GPS capable options. In Today's era high speed video surveillance is very crucial from security point of view. Public safety services below $1 \mathrm{GHz}$ is mainly used for voice services, while 4.9 GHz Public Safety WLAN is used for video surveillance services. Accordingly, a frequency reconfigurable antenna using MEMS switches is reported in [1] for three bands $800 \mathrm{MHz}, 2.4 \mathrm{GHz}$ and $4.9 \mathrm{GHz}$ of Public Safety spectrum, but antenna structure is costlier and experimental validation is not done. Simulation results with peak gain only is discussed. A multilayer MEMS integrated antenna is reported in [2] for 700 to $900 \mathrm{MHz}$ band of public safety radio. A broadband and compact antenna below $1 \mathrm{GHz}$ is discussed in [3]. Simulation study of quad band antenna covering public safety spectrum is reported in [4], antenna structure is very complex. Simulated results of CPW fed slot antenna with a compact structure, high gain and high efficiency is presented in [5] for $4.9 \mathrm{GHz}$ band of public safety applications, but results are not experimentally verified. Antenna with fractal ground structure is discussed in [6] for emergency management, without experimental verification. A dual band compact fractal antenna for emergency management is discussed in [7] covers $4.9 \mathrm{GHz}$ band of public safety with high gain but ground plane with 
metallic plate is very large i.e $600 \mathrm{~mm}$. An I shaped fractal antenna is available in [8] for emergency management, covers vehicular communication application and other Wireless $\mathrm{C}$ band applications, not cover Public safety WLAN. A simple and cost-effective design dedicated to high speed video surveillance application may be designed using simple conventional patch like rectangular, circular and triangular etc. Microstrip antenna are fed with different non-contact and contact feeding techniques such as proximity coupling, aperture coupling, coaxial feed and microstrip feed. Microstrip feed line is simplest in structure and easy to fabricate [9], [10]. Substrate thickness, dimension of patch and ground effect performance parameters like bandwidth, resonant frequency and gain of antenna. To achieve required performance, a lot of tradeoff is required in dimensional parameters like length of patch, substrate thickness, ground plane and feed width of antenna. So, antenna design itself look like a complex optimization problem [11], [12]. Coupling between adjoining elements of antenna array makes situation more complicated. Problem of coupling is more in rectangular and circular configurations. Accordingly, there are distinct set of design for triangular microstrip patch antenna like $30^{\circ}-60^{\circ}-$ $90^{\circ}, 45^{\circ}-45^{\circ}-90^{\circ}$, equilateral etc. are reported, size of equilateral triangular microstrip antenna (ETMA) among other configurations is compact and it is more directive [13], [14] . An equilateral triangular patch antenna design with optimization of resonant frequency using particle swarm optimization is reported in [15] for dual frequency operation, in this paper optimization of only one parameter is discussed. Moreover, RT duriod substrate is used, which is more expensive than FR4. A rounded corner equilateral triangular patch antenna is reported in [16] for RFID applications. The design of aperture coupled equilateral triangular antenna array is reported in [17] for dual band operation, but design is complicated due to two-layer configuration. A modification in $1 \times 2$ antenna array ground plane reported in [18] to reduce mutual coupling, modification is done in ground plane for $2.6 \mathrm{GHz}$. Further a comparison between rectangular and triangular array has been done. Parameters for $1 \times 2$ and $1 \times 4$ triangular antenna array design also discussed, which provide a good reference for proposed antenna array design [19].

Thus, none of the design of equilateral triangular array discussed in literature modified in terms of corner truncation to parasitic reactance and to improve overall performance of design. Whale Optimization algorithm also applied in field of antenna engineering on multiple dimensions [20]. Accordingly, after a brief literature review, proposed antenna is considered for public safety application.

\section{Antenna Design}

The Antenna is designed on a FR4 substrate of thickness $1.58 \mathrm{~mm}$ with dielectric constant 4.4 and loss tangent of 0.017 , because FR4 has flame resistant properties and good strength [21]. A microstrip feed is used to achieve the matching with the patch antenna. Firstly, triangular microstrip patch antenna is designed using HFSS Simulator and after simulation, optimization of basic triangular shape is done using whale optimization algorithm. Then basic triangular shape is simply modified by filleted corner as well as feed and circular cut in feed to improve the performance and same is tuned for desired application. Finally, by utilizing the modified antenna elements $1 \times 2$ and $2 \times 2$ array is developed with better performance in terms of gain. Following are the design steps:

\subsection{Conventional Triangular patch antenna (CTPA)}

All the dimensions of the patch antenna have been calculated from the mathematical expressions [13] as given by equation (1),(2),(3) and (4). From Equation (1), side length of patch antenna is computed by making use of dielectric constant and given frequency. Effective dielectric constant is calculated by using side length from equation (2). Effective side length as well as resonant frequency by making use of effective side length calculated from (3) and (4). Synthesized antenna performance is examined as per intended application. In Table 1, geometric design parameters triangular patch antenna (Fig. 1.) are given.

(a) Computation of side length

$$
a=2 c / 3 f_{r} \sqrt{\varepsilon_{r}}
$$

(b) The effective dielectric constant of the Triangular microstrip patch antenna

$$
\varepsilon_{e f f}=\frac{1}{2}\left(\varepsilon_{r}+1\right)+\frac{1}{4} \frac{\left(\varepsilon_{r}-1\right)}{\sqrt{1}+12 \frac{h}{a}}
$$

(c) The effective side length of patch (L)

$$
\begin{aligned}
& a_{e f f}=a+\frac{h}{\sqrt{\varepsilon_{r}}} \\
& f_{r}=2 c / 3 a_{e f f} \sqrt{\varepsilon_{e f f}}
\end{aligned}
$$

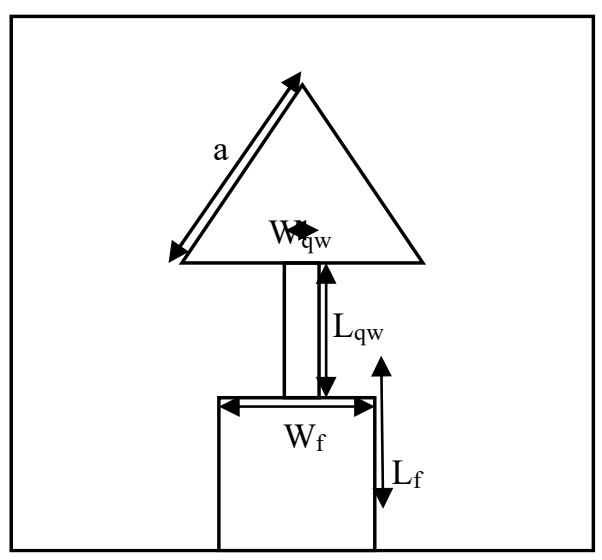

Figure 1: Conventional triangular patch antenna 
Table 1: Design parameters of patch antenna

\begin{tabular}{|c|c|c|}
\hline S. No. & Parameters & Value $(\mathrm{mm})$ \\
\hline 1 & Side Length (a) & 19.5 \\
\hline 2 & Feed width $\left(\mathrm{W}_{\mathrm{f}}\right)$ & 2.8 \\
\hline 3 & Feed length $\left(\mathrm{L}_{\mathrm{f}}\right)$ & 4 \\
\hline 4 & $\begin{array}{c}\text { Quarter wave Transformer } \\
\text { length }(\text { Lqw) }\end{array}$ & 7.7 \\
\hline 5 & Quarter wave Transformer & 0.7 \\
& width(Wqw) & $30 \times 30$ \\
\hline 6 & Ground plane $(\mathrm{L} \times \mathrm{W})$ & \\
\hline
\end{tabular}

\subsection{Optimization of basic triangular patch antenna}

Mathematical relation between output and input parameters built in MATLAB using polyfit function [11]. It evaluates graphically goodness of fit using prediction bound and residuals. Performance of the design can be predicted by creating the equations which best apposite to the trial data, this technique of curve fitting used to find the relation between the length and the resonant frequency of the triangular microstrip patch antenna mathematically. To represent mathematical relations between the lengths and resonant frequency, reflection coefficient and width of feed line, ground and gain of antenna data is developed with the Ansoft High frequency structural simulator (HFSS). Side length, Width of quarter wave transformer, ground plane length and is optimized to obtain the required working frequency and best value of gain and reflection coefficient for antenna These relations is expressed in the form of polynomial equation leads to corresponding objective function. Whale Optimization Algorithm is applied by using these equations to get optimized Triangular patch antenna. In this process firstly, whale search for prey then it encircles the prey by spiral movement. In the final stage, it attacks the prey according to equations given below. Mathematically WOA basically perform three basic steps: Search, encircling and attacking

Depending on value of variables probability $\mathrm{p}$, random vector $\vec{A}$ position is updated according to equations (5), (6) and (7):

$\overrightarrow{\mathrm{B}}=\overrightarrow{\mathrm{C} \mathrm{Y}^{*}}(\mathrm{t})-\overrightarrow{\mathrm{Y}}(\mathrm{t})$

$\mathrm{Y}(\mathrm{t}+1)=\mathrm{Y}_{\text {rand }}-\mathrm{A} \cdot \mathrm{B}$

$Y(\mathrm{t}+1)=\overrightarrow{B^{\prime}} e^{b l} \cdot \cos (2 \pi l)+\overrightarrow{\mathrm{Y}^{*}}(\mathrm{t})$

Where $\mathrm{t}$ denotes current iteration, $\mathrm{A}$ and $\mathrm{C}$ are coefficient vectors, $\mathrm{Y}^{*}$ is the position vector of the best solution. Where $\overrightarrow{\mathrm{B}}=\left|\overrightarrow{\mathrm{Y}^{*}}(\mathrm{t})-\overrightarrow{\mathrm{Y}}(\mathrm{t})\right|$ and indicates the $\mathrm{i}$ th whale distance to target, $b$ is a constant for defining the logarithmic spiral shape, $l$ is a number between $[-1,1]$, and. is an element-byelement multiplication [22]. WOA is preferably used because success rate of WOA algorithm is high in solving challenging problems. There are some other advantages such as high local optima avoidance and convergence speed simultaneously, Lesser no of internal parameters are to be adjusted, smoothly transition between exploration and exploitation and as iteration increase convergence is to be accelerated.

Fitness function is minimized by using WOA so that optimum value of side length, width of quarter wave transformer, length of ground plane is achieved at desired frequency. Input parameters of WOA to apply on given fitness function is shown in Table 2.

Table 2: Input Parameters of WOA

\begin{tabular}{|c|c|c|}
\hline S. No. & Parameters & $\begin{array}{c}\text { Parameter } \\
\text { value }\end{array}$ \\
\hline 1 & Number of Search Agents & 30 \\
\hline 2 & Lower Bound for Side Length & 16 \\
\hline 3 & Upper Bound for side length & 20 \\
\hline 4 & $\begin{array}{c}\text { Lower bound for height of } \\
\text { substrate }\end{array}$ & 1 \\
\hline 5 & Upper bound for height of \\
substrate & 3 \\
\hline 6 & Lower bound for qw & 0.3 \\
\hline 7 & Upper bound for qw & 0.9 \\
\hline 8 & Lower bound for ground & 2 \\
\hline 9 & Upper bound for ground & 30 \\
\hline 10 & Dimensions & 4 \\
\hline 11 & Max Iterations & 500 \\
\hline
\end{tabular}

\subsection{Synthesis of triangular patch antenna array}

Three different designs of antenna are simulated (1) modified triangular patch antenna (MTPA) (2) $1 \times 2$ modified patch antenna array (3) $2 \times 2$ modified patch antenna array. Basic patch antenna is optimized initially to get necessary working frequency, gain and bandwidth. Sharp bends at corner causes parasitic reactance which change in performnce of antenna. Parasitic reactance is overcome by chamfering and filleting [23]. Then basic patch antenna is modified in the form of filleted corner to reduce parasitic reactance. Reflection coefficient has been improved by cutting slot of circular shape in the feed line. A circular cut is also to get the novelty in shape. These novelties helped to improved performance of basic patch antenna. Modified triangular patch antenna with rounded corner and cut in feed is shown in the Fig. 2(a). This antenna is transformed into $1 \times 2$ array to enhance gain with same resonating frequency. In order to enhance the gain further $2 \times 2$ antenna is designed. Outer edge vertices of power divider network for array design also filleted for improved performance. To reduce cross coupling spacing between antenna elements is tuned. $1 \times 2$ antenna array is shown in Fig. 2(b). and $2 \times 2$ antenna 
array with all dimensions (in $\mathrm{mm}$ ) shown in Fig. 3. respectively.

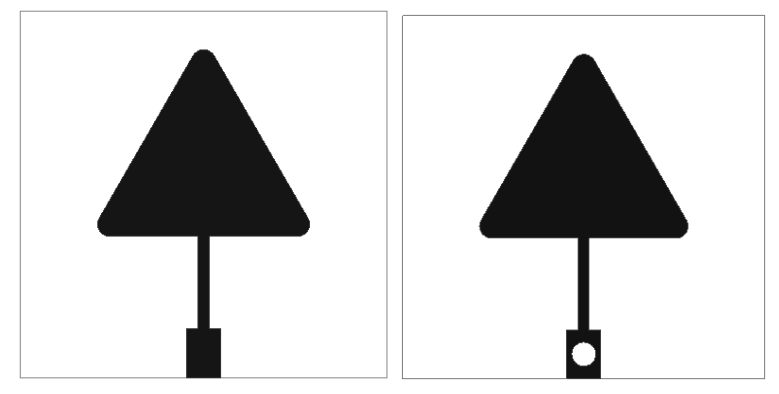

(a)

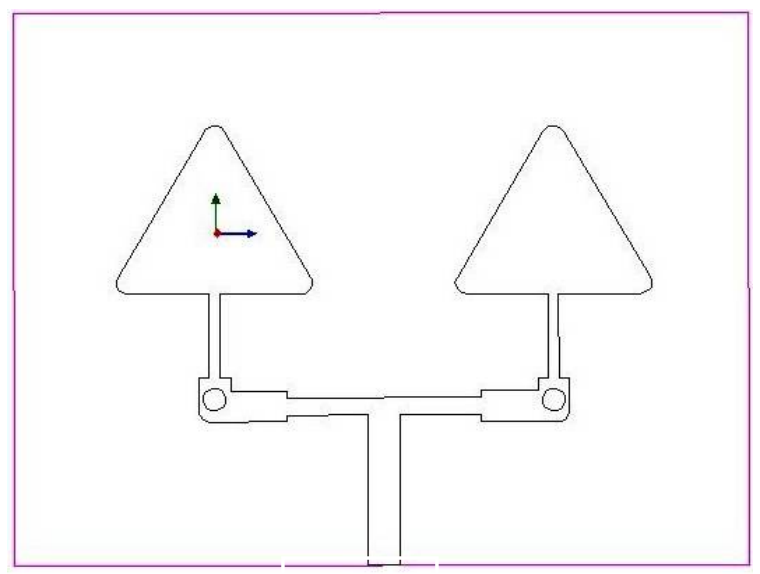

(b)

Figure 2: (a) Modified triangular patch antenna (b)Modified $1 \times 2$ triangular patch antenna array

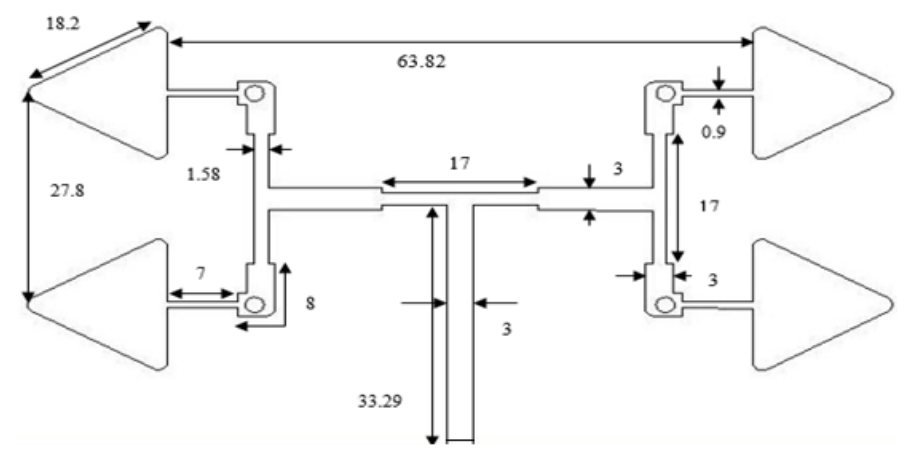

Figure 3: $2 \times 2$ Modified Triangular antenna $\operatorname{array}($ All dimensions are in $\mathrm{mm} \mid)$

\section{Discussions}

\subsection{Performance Analysis of Triangular Patch Antenna}

\subsubsection{Side length variation effect}

It is clear from equation (1), side length of patch varies inversely to the resonant frequency of antenna. As side length is changed resonant frequency also shifts. Side length is calculated from the given equation (1), but antenna does not properly resonate at desired frequency. So, by using polynomial relation between side length and frequency, optimization of side length is done with WOA to achieve required frequency. Polynomial formed by basic curve fitting given below:

$\mathrm{F}=0.0002665833 \mathrm{a}^{5}-0.024 \mathrm{a}^{4}+0.86367 \mathrm{a}^{3}-15.534 \mathrm{a}^{2}+139.4 \mathrm{a}-$ 492.449

this polynomial equation along with fitness function applied in WOA to find the optimum value of side length for exact frequency.

Fitness Function $=(4.9-\mathrm{F})^{\wedge} 2$

Optimized side length is $18.21 \mathrm{~mm}$ which was 19.48 earlier calculated by formula for side length calculation. It is shown in Fig. 4., that after applying optimized side length $18.21 \mathrm{~mm}$ for designing antenna desired frequency is achieved.

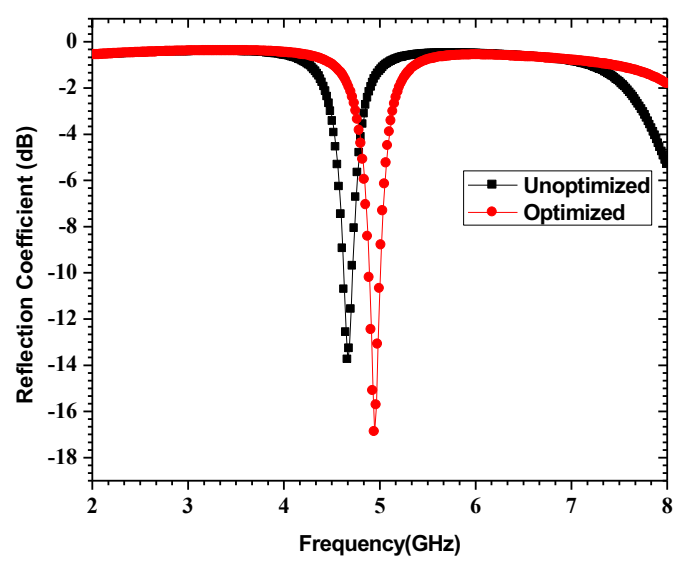

Figure 4: Comparative analysis of S11 of CTPA for side length variation

\subsubsection{Effect of quarter wave transformer width}

Quarter wave transformer matches patch impedance and feed line impedance, length of quarter wave transformer as specified by name is always $\lambda / 4$ but width affects the matching as width is changed, reflection coefficient are changed. A relation is developed between transformer width and Reflection Coefficient using basic curve fitting as given below:

$R F=510 q w^{4}-1200 q w^{3}+1000 q w^{2}-380 q w+52$

Objective Function $=(25+\mathrm{RF})^{2}$

By using the given equation (10), objective function is minimized by WOA. Comparison between result at initially calculated width of quarter wave and at optimized width shown in Fig. 5. Initially at $0.7 \mathrm{~mm}$ reflection coefficient is 
-16.89 $\mathrm{dB}$ and after optimization quarter wave transformer width found to be $0.9 \mathrm{~mm}$ and is improved up to $-24.65 \mathrm{~dB}$.

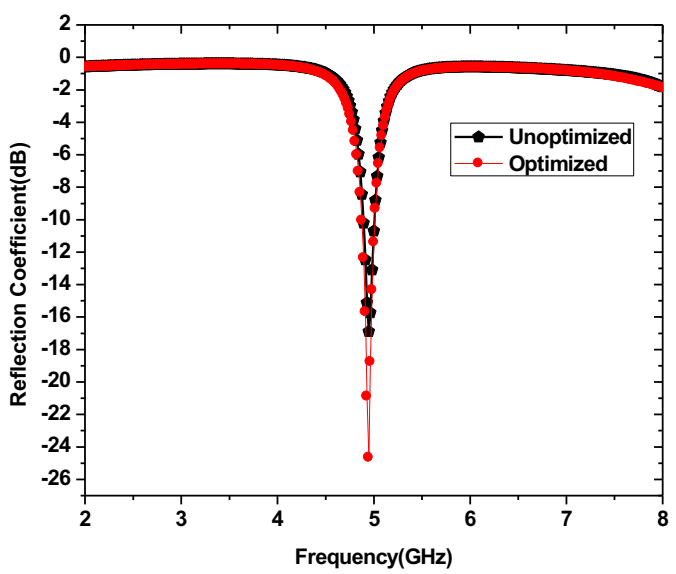

Figure 5: Comparative analysis of S11 of CTPA for quarter wave width variation

\subsubsection{Ground plane variation effect}

Ground plane in microstrip feeding plays a significant role in shaping radiation of patch antenna. As ground plane length is varied, and it has seen that ground plane variation affects the gain of antenna marginally. Here a relation is developed between ground plane length and gain of antenna using basic curve fitting as given below:

gain $=0.0000043 \mathrm{~g}^{4}-0.00025 \mathrm{~g}^{3}+0.005 \mathrm{~g}^{2}-0.038 \mathrm{~g}+1.087$

Objective function $=(1.18 \text {-gain })^{2}$

By using the given equation (12), fitness function is minimized by WOA and an optimized length of ground plane is calculated which is $30 \mathrm{~mm}$ and gives a gain of $1.18 \mathrm{~dB}$ as shown in Table 3 .

Table 3:. Results of Optimized Basic Triangular Patch Antenna

\begin{tabular}{|c|c|c|c|}
\hline S.No & Parameter & Without Optimization & With Optimization \\
\hline 1. & Side Length & $19.5 \mathrm{~mm}$ & $18.21 \mathrm{~mm}$ \\
\hline 2 & $\begin{array}{c}\text { Resonant } \\
\text { Frequency }\end{array}$ & $4.7 \mathrm{GHz}$ & $4.9 \mathrm{GHz}$ \\
\hline 3 & $\begin{array}{c}\text { Reflection } \\
\text { coefficient }\end{array}$ & $-16.89 \mathrm{~dB}$ & $-24.65 \mathrm{~dB}$ \\
\hline 4 & Gain & $1.04 \mathrm{~dB}$ & $1.18 \mathrm{~dB}$ \\
\hline
\end{tabular}

\subsection{Performance Analysis Modified Triangular Patch Antenna (MTPA)}

Antenna performance parameters i.e. gain and reflection coefficient shown in Fig. 6. and Fig. 7 depicts that Gain of the modified patch antenna in form of fillet corner improves from $1.18 \mathrm{~dB}$ to $1.25 \mathrm{~dB}$, that shows $0.07 \mathrm{~dB}$ improvement over CTPA. Antenna radiate at $4.9 \mathrm{GHz}$ covers 4.94 to 4.99
$\mathrm{GHz}$ band.. A circular cut in feed line shows a imrovement in terms of reflection coefficient shown in Fig. 7. Radiation pattern in $\mathrm{XZ}$ and $\mathrm{YZ}$ plane is shown in Fig. 8. which shows a major lobe in front of patch and gain of antenna is 1.18 $\mathrm{dB}$.

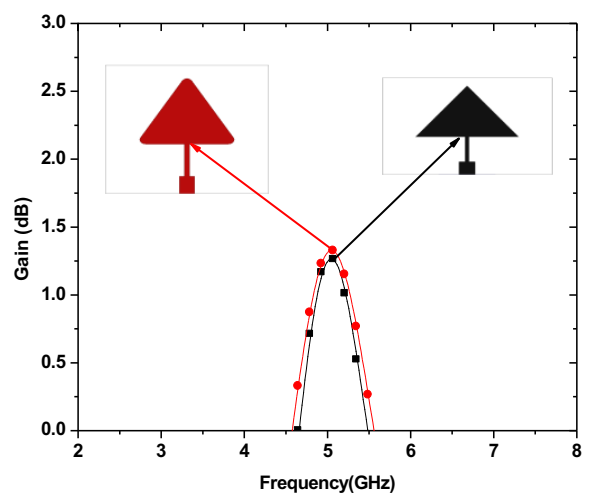

Figure 6: Comparative analysis of gain of MTPA with and without fillted corner

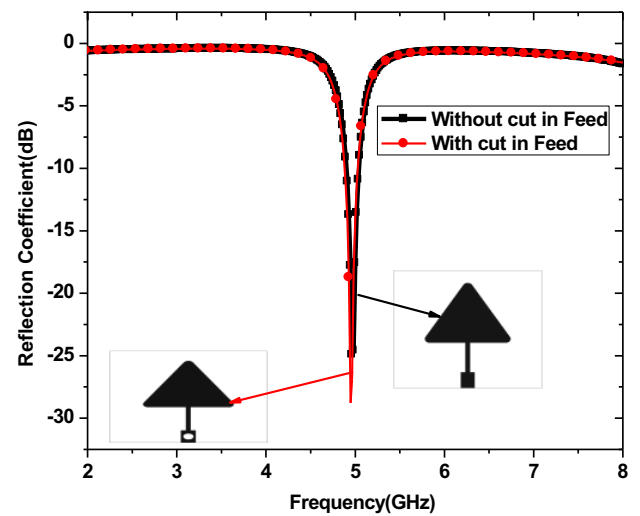

Figure 7: Comparative analysis of S11 of MTPA with and without circular cut in feed

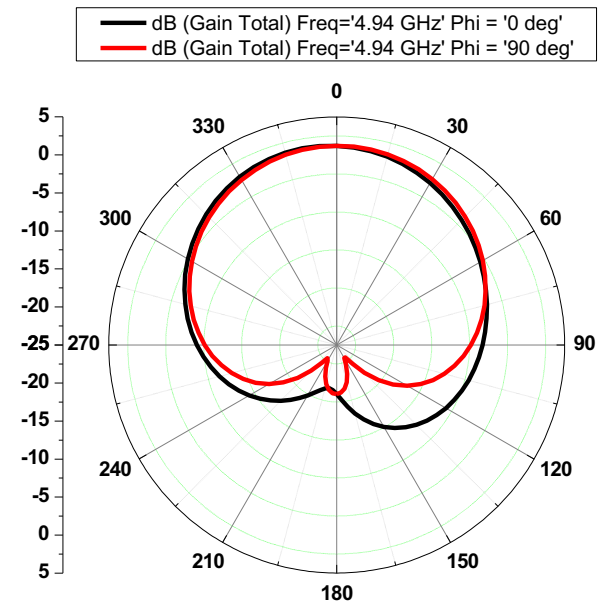

Figure 8: Radiation pattern of MTPA at $4.94 \mathrm{GHz}$ 


\subsection{Performance Analysis of $1 \times 2$ Modified Triangular Patch Antenna Array (MTPAA)}

After designing the single modified printed patch antenna having triangular shape with rounded corner, to improve the antenna performance parameter like gain, $1 \times 2$ antenna array has been designed. Reflection coefficient of $1 \times 2$ antenna array is shown in Fig. 9., which is found to be $-16.36 \mathrm{~dB}$. Radiation pattern is shown in Fig. 10., shows that antenna has gain of $5.36 \mathrm{~dB}$ which is significant improvement over modified triangular patch antenna.

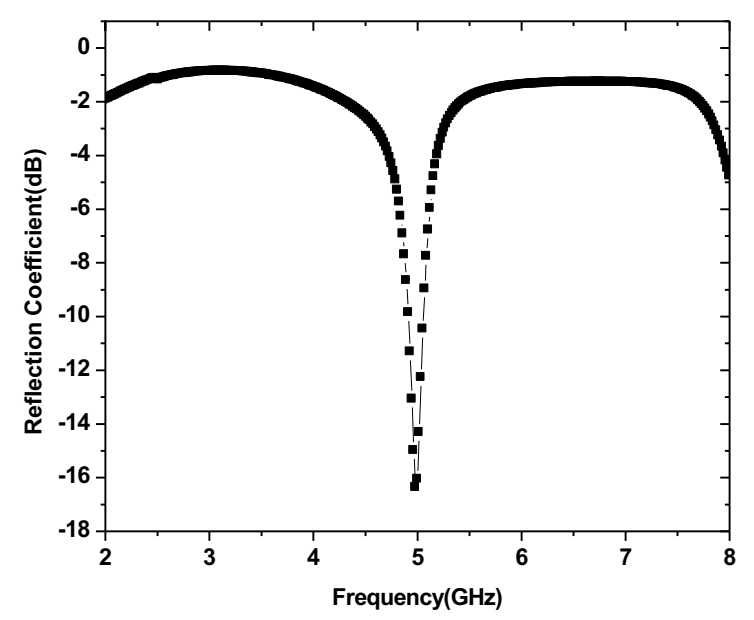

Figure 9: Reflection coefficient of $1 \times 2$ MTPAA at 4.98

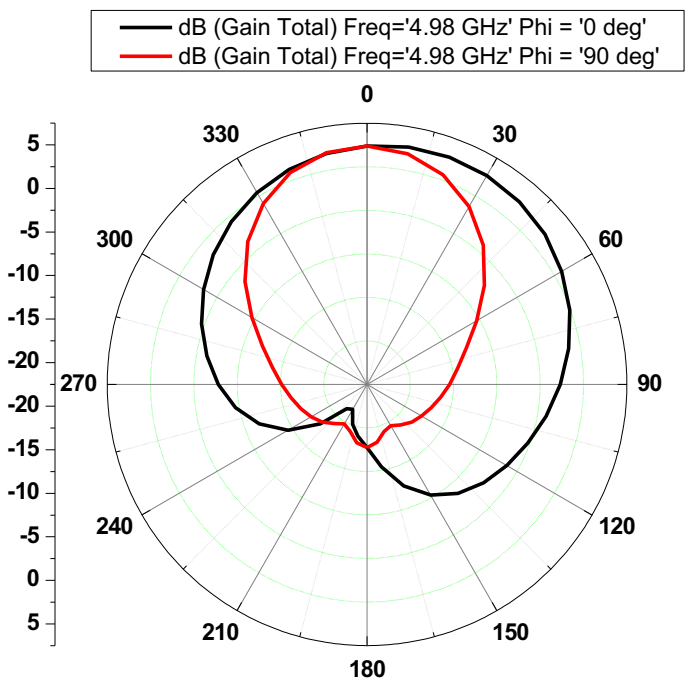

Figure 10:Radiation pattern of $1 \times 2$ MTPAA at $4.98 \mathrm{GHz}$

\subsection{Performance Analysis of Proposed $2 \times 2$ Modified Triangular Patch Antenna Array}

Reflection coefficient of $2 \times 2$ antenna array is shown in Fig. 11 , which is found to be $-15.87 \mathrm{~dB}$. The proposed antenna array has been optimized to operate at $4960 \mathrm{MHz}$ with a bandwidth of $120 \mathrm{MHz}$ from 4900-5020 MHz (fractional bandwidth of $2.4 \%$ ) which is more than enough for the targeted application i.e. Public safety WLAN, requires a fractional operating bandwidth of $1 \%(4940-4990$
$\mathrm{MHz}$ ) and also it helps to reduce interference from other nearby operating applications. Radiation pattern in Fig. 12 shows that antenna array has gain of $6.69 \mathrm{~dB}$ in direction of radiation pattern, which is significant improvement over $1 \times 2$ modified triangular patch antenna array.

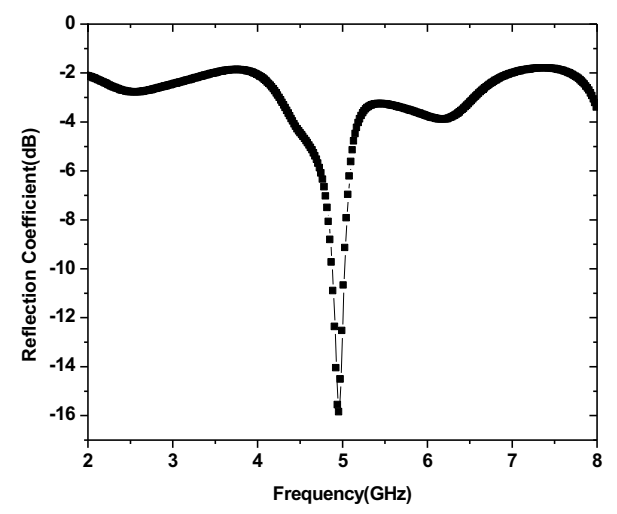

Figure 11: Reflection coefficient of $2 \times 2$ MTPAA at $4.98 \mathrm{GHz}$

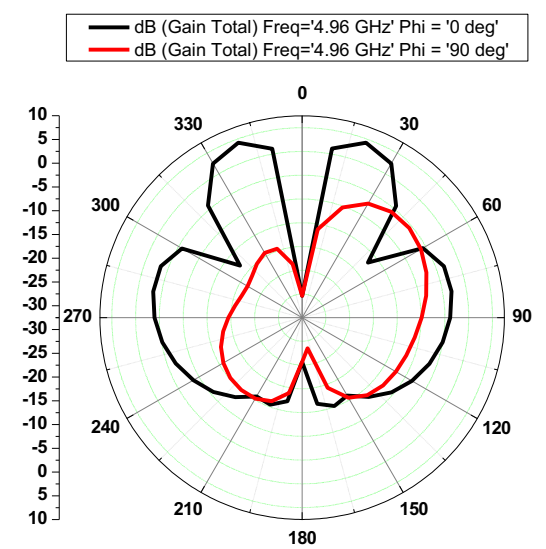

Figure 12:Radiation pattern of $2 \times 2$ MTPAA at $4.98 \mathrm{GHz}$

\subsection{Experimental Validation}

Finally, $2 \times 2$ triangular array is fabricated and reflection coefficient is measured using Anritsu MS46322A vector network analyzer shown in Fig. 13. Fabricated results are quite matched with simulated results as shown below in Fig. 14. Radiation pattern are measurent image of antenna at is shown in Fig. 15. Radiation pattern are mesured at $\varphi=0^{\circ}$ and $\varphi=90^{\circ}$, in $\mathrm{YZ}$ and $\mathrm{XZ}$ plane. Measured radiation pattern are matched with simulated results shown in Fig. 16.

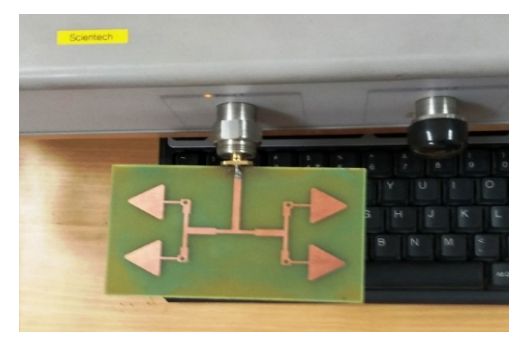

Figure 13:S11 measurement of $2 \times 2$ MTPAA 


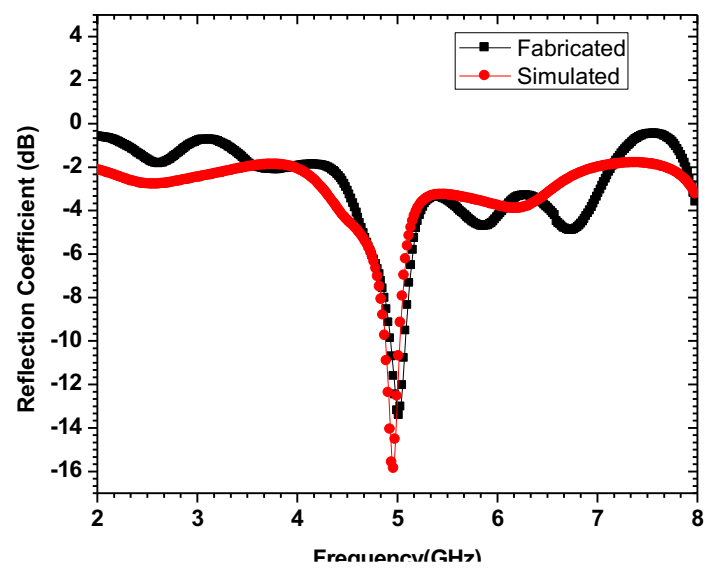

Figure 14: Comparison of S11 of simulated and fabricated $2 \times 2$ MTPAA

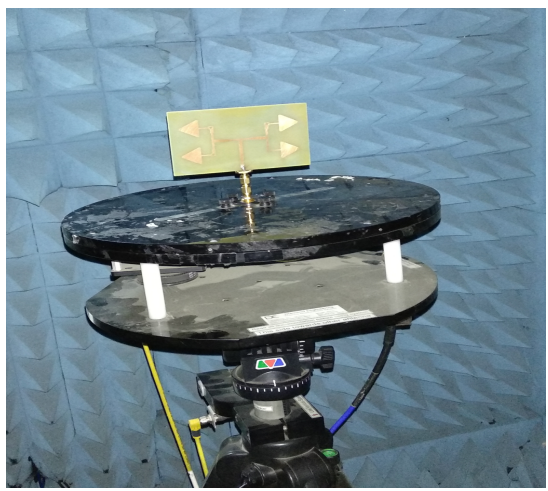

Figure 15: Anechoic chamber image of antenna

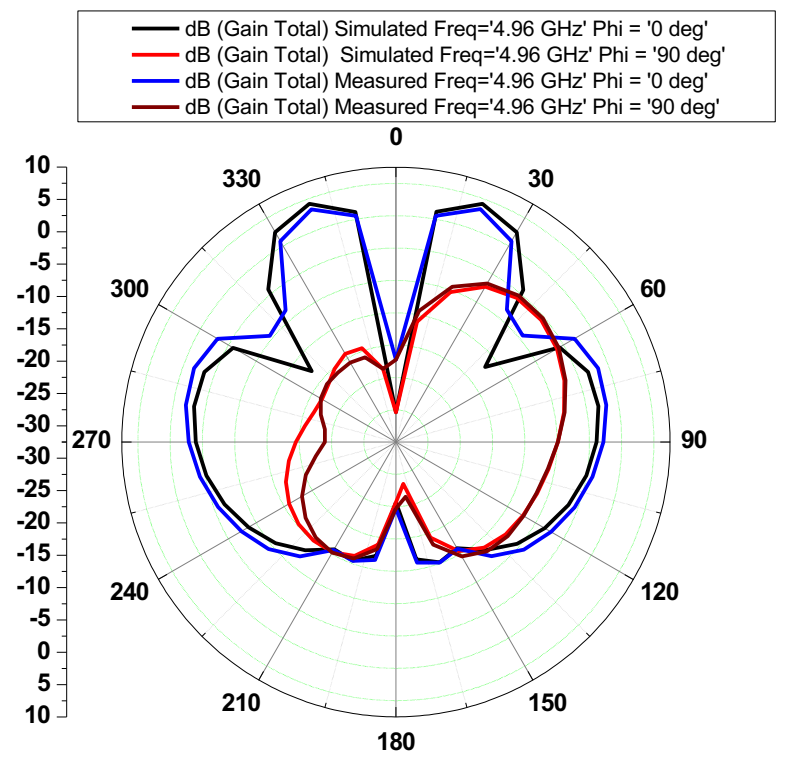

Figure 16: Comparison of simulated and measured radiation pattern of antenna
Table 4 Final Comparison Table of Performance parameters

\begin{tabular}{|c|c|c|c|c|}
\hline Parameters & CTPA & MTPA & $\begin{array}{l}1 \times 2 \\
\text { Element } \\
\text { MTPAA }\end{array}$ & $\begin{array}{l}2 \times 2 \\
\text { Element } \\
\text { MTPAA }\end{array}$ \\
\hline $\begin{array}{l}\text { Resonant } \\
\text { Frequency } \\
(\mathrm{GHz})\end{array}$ & 4.94 & 4.94 & 4.98 & 4.96 \\
\hline $\begin{array}{l}\text { Reflection } \\
\text { coefficient } \\
\text { (dB) }\end{array}$ & -24.65 & -28.77 & -16.36 & -15.87 \\
\hline Gain (dB) & 1.18 & 1.25 & 5.36 & 6.69 \\
\hline $\begin{array}{l}\text { Bandwidth } \\
(\mathrm{MHz})\end{array}$ & 140 & 120 & 130 & 120 \\
\hline
\end{tabular}

It is clearly observed from table 4 that modified triangular patch antenna improved over conventional triangular patch antenna in terms of reflection coefficient and gain. $1 \times 2$ and $2 \times 2$ antenna array resonates at same frequency meet the band requirement for public safety and has an enhanced gain, which is $\mathbf{4 3 . 5 2} \%$ improvement over modified triangular patch antenna.

\section{Conclusions}

Modified triangular patch antenna array with $2 \times 2$ element configuration is designed using optimized unit MTPA for public safety application with improved performance in terms of gain. Proposed antenna array resonates at $4.9 \mathrm{GHz}$ with a bandwidth of $120 \mathrm{MHz}$, more than specified bandwidth for public safety application. Novelty lies in design of proposed antenna array itself with improved performance. Whale optimization algorithm along with curve fitting proved to be an effective alternative for optimization of patch antennas. Effectiveness of Whale Optimization Algorithm is proved in antenna design by successfully optimizing three geometric parameters. Future work would focus on achieving multiple bands for public safety using fractal geometry and improving the bandwidth and gain by multi element array.

\section{Acknowledgements}

The authors express sincere thanks to the Faculty and Staff of the ECE Department at SLIET, Longowal, NITTTR Chandigarh and IIT delhi for making the Laboratory Facilities available for the present work

\section{References}

[1] X. Yuan, Y. Damgaci, H. Mopidevi, and B. A. Cetiner, "RF-N/MEMS Integrated Reconfigurable Antenna for Public Safety Applications," IEEE Int. 
symosium antenna Propag. Soc., pp. 1-4, 2009.

[2] A. Khoshniat, H. Mopidevi, Y. Damgaci, D. Rodrigo, L. Jofre, and B. A. Cetiner, "Mems Integrated Reconfigurable Antenna for Cognitive Public Safety Radios," in Proceedings of the Fourth European Conference on Antennas and Propagation, 2010, pp. 1-3.

[3] H. Mopidevi, D. Rodrigo, O. Kaynar, L. Jofre, and B. A. Cetiner, "Compact and broadband antenna for LTE and public safety applications," IEEE Antennas Wirel. Propag. Lett., vol. 10, pp. 1224-1227, 2011.

[4] H. Mopidevi, Y. Damgaci, D. Rodrigo, L. Jofre, and B. A. Cetiner, "A quad-band antenna for public safety applications," IEEE Antennas Wirel. Propag. Lett., vol. 13, pp. 1231-1234, 2014.

[5] K. Rammoorthyraju and P. P. Kumar, "Design of CPW-fed dual-folded slot patch antenna for $4.9 \mathrm{GHz}$ public safety spectrum," in International Conference on Information Communication and Embedded Systems (ICICES2014), 2014, no. 978, pp. 1-5.

[6] S. Kakkar and S. Rani, "A novel antenna design with fractal-shaped DGS using PSO for emergency management," Int. J. Electron. Lett., vol. 1, no. 3, pp. 108-117, Sep. 2013.

[7] L. Lizzi, R. Azaro, G. Oliveri, and A. Massa, "Multiband Fractal Antenna for Wireless Communication Systems for Emergency Management," J. Electromagn. Waves Appl., vol. 26, no. 1, pp. 1-11, Jan. 2012.

[8] S. Kakkar, T. S. Kamal, and A. P. Singh, "On the Design and Analysis of I-Shaped Fractal Antenna for Emergency Management," IETE J. Res., pp. 110, Jan. 2018.

[9] C.A.Balanis, Antenna Theory Analysis and Design, Second Edi. Wiley India Pvt. Ltd., 2008.

[10] L. S. Singh,Gurmeet;Solanki, "Design and Analysis of Dual Band Printed Microstrip Dipole Antenna for WLAN," in IJCA Proceedings on International Conference on Advancements in Engineering and Technology, 2015, pp. 9-11.

[11] S. Rani and A. P. Singh, "On the design and optimisation of new fractal antenna using PSO," Int. J. Electron., vol. 100, no. 10, pp. 1383-1397, 2013.

[12] A. Kumar and A. Partap, "On the Design of $2 \times 2$ Element Fractal Antenna Array using Dragonfly Optimization," Int. J. Comput. Appl., vol. 179, no. 33, pp. 27-34, Apr. 2018.

[13] Nasimuddin, K. Esselle, and A. K. Verma, "Resonance frequency of an equilateral triangular microstrip antenna," Microw. Opt. Technol. Lett., vol. 47, no. 5, pp. 485-489, Dec. 2005.
[14] B. Singh and K. P. Ray, "A 50-X microstrip line fed shorted equilateral triangular microstrip antenna," Microw Opt Technol Lett., vol. 60, pp. 1219-1222, 2018.

[15] P. Pratap, R. S. Bhatia, and B. Kumar, "Design and simulation of equilateral triangular microstrip antenna using particle swarm optimization ( PSO ) and advanced particle swarm optimization ( APSO ),"Sädhanā, vol. 41, no. 7, pp. 721-725, 2016.

[16] N. Misran et al., "A Rounded Corner Triangular patch Antenna For Dual- Frequency Application," Microw. Opt. Technol. Lett., vol. 56, no. 1, pp. 69$72,2014$.

[17] G. M. Pushpanjali, R. B. Konda, S. N. Mulgi, and S. K. Satnoor, "Equilateral Triangular Microstrip Array Antenna For Broadband Operation," Microw. Opt. Technol. Lett., vol. 50, no. 7, pp. 1834-1837, 2008.

[18] F. Y. Zulkifli, E. T. Rahardjo, and D. Hartanto, "RADIATION PROPERTIES ENHANCEMENT OF TRIANGULAR PATCH MICROSTRIP ANTENNA ARRAY USING HEXAGONAL DEFECTED GROUND STRUCTURE," Prog. Electromagn. Res. M, vol. 5, pp. 101-109, 2008.

[19] Y. S. H. Khraisat and M. M. Olaimat, "Comparison between rectangular and triangular patch antennas array," in 2012 19th International Conference on Telecommunications (ICT), 2012, pp. 1-5.

[20] G. Singh and A. P. Singh, "On the design of planar antenna using Fibonacci word fractal geometry in support of public safety," Int. J. RF Microw. Comput. Eng., vol. 29, no. 2, p. e21554, Feb. 2019.

[21] T. P. T. Aguilar JR, Beadle M, "The microwave and RF characteristics of FR4 substrates," in IEE Colloquium on Low Cost Antenna Technology (Ref. No. 1998/206), pp. 2-6.

[22] S. Mirjalili and A. Lewis, "The Whale Optimization Algorithm," Adv. Eng. Softw., vol. 95, pp. 51-67, 2016.

[23] L. S. Solanki, S. Singh, and D. Singh, "Modified Wideband Bowtie Antenna for WLAN and High Speed Data Communication Applications," Wirel. Pers. Commun., vol. 95, no. 3, pp. 2649-2663, Aug. 2017. 